\title{
The Effect of English Language Learning on Creative Thinking Skills: A Mixed Methods Case Study
}

\author{
Sandro Sehic ${ }^{1}$ \\ ${ }^{1}$ MVCC Education Opportunity Center, Mohawk Vally Community College, Utica, NY, USA \\ Correspondence: Sandro Sehic, MVCC Education Opportunity Center, Mohawk Valley Community College, \\ Utica, NY, USA. Tel: 315-534-9262. E-mail: ssehic@roadrunner.com
}

Received: November 23, 2016

Accepted: February 6, 2017 Online Published: February 7, 2017

doi: $10.5539 /$ elt.v10n3p82

URL: http://doi.org/10.5539/elt.v10n3p82

\begin{abstract}
The purpose of this sequential explanatory mixed-methods case study was to investigate the effects of English language learning on creative thinking skills in the domains of fluency, flexibility, originality, and elaboration as measured with the Alternate Uses Test. Unlike the previous research studies that investigated the links between English language learning and cognitive skills and had large numbers of participants, this research study relied on small group of participants to provide detailed information about the effects of English language learning on their creative thinking skills in the domains of fluency, flexibility, originality, and elaboration as measured with the Alternate Uses Test. This study involved the collection of quantitative data at the pretest and posttest stages and the explanation of the quantitative data using qualitative data. The quantitative findings of this sequential explanatory mixed-method case study indicated that there were no statistically significant differences between the pretest and posttest results in the domains of fluency, flexibility, originality, and elaboration as measured with the Alternate Uses Test.
\end{abstract}

Keywords: ESL, English language learning, second language learning, creativity, creative thinking skills

\section{Introduction}

The literature review has revealed multiple studies conducted within the past ten years that investigate the links between bilingualism and cognitive skills. A significant body of studies suggests that positive relationship may exist between bilingualism and cognitive skills.

In their meta-analysis, which reviewed numerous research studies about bilingualism and cognitive skills, Adescope, Laving, Thompson, \& Ungerleider (2010), suggested that bilingualism had positive relationships with cognitive skills such as metalinguistic awareness, enhanced metacognitive skills, stronger symbolic representation and abstract reasoning skills, enhanced problem-solving skills, enhanced creative and divergent thinking skills, and greater cognitive flexibility. Further research studies by Kushalangar, Hannay, and Hernandez (2010), Soveri, Laine, Hämäläinen, and Hugdahl (2011), Marzecová, Asanowicz, Krivá, and Wodniecka (2013), Prior and Macwhinney (2010), Filippi, Leech, Thomas, Green, and Dick (2012), and Hernández, Costa, Fuentes, Vivas, and Sebastián-Gallés (2010) suggested that bilingualism had a positive relationship with executive functions in the domain of cognitive control among late bilinguals.

The results of a number of studies that investigated the links between bilingualism and cognitive skills among children suggested that bilingualism among children had positive relationships with cognitive skills. Research studies by Poulin-Dubois, Blaye, Coutya, and Bialystok (2011), Lauchlan, Parisi, and Fadda (2012), Greenberg, Bellana, and Bialystok (2013), Kalashnikova and Mattock (2014), Adi-Japha, Berberich-Artzi, and Libnawi (2010), Kempert, Hardy, and Saalbach (2011), Steby, Sindhupriya, Rupali, and Swapna (2010), and Yang, Yang, and Lust (2011) suggested that positive relationships existed between bilingualism and executive functions among bilingual children.

Based on the results of the previous research studies that investigated the links between bilingualism and cognitive skills, one can hypothesize that bilingual individuals have stronger cognitive skills than monolinguals. However, the studies in question did not explain what caused the stronger cognitive skills among bilinguals. Is it possible that individuals with stronger cognitive skills are more likely to acquire knowledge of a second language or that learning a second language improves learners' creative thinking skills? In addition, the literature 
review revealed that a limited number of recent research studies explored the relationship between learning a second language and one specific cognitive skill.

In the past five years, researchers have become interested in the links between creative thinking skills and second languages. Romero, Hyvönen, and Barbera (2012) and Sternberg (2003) described creative thinking skills or, simply, creativity as the ability to produce novel things, ideas, and solutions to everyday problems. Halim, Kingsbury, and Drage (2013), Milbrandt and Milbrandt (2011), and Pishghadam, Khodadady, and Zabihi (2011) argued that sufficient research had not been conducted on creativity, a significant part of human intelligence, whereas Meera and Remya (2010) and Pishghadam et al. (2011) argued that sufficient research had not been conducted on creativity in the domain of second language learning.

Research studies by Pishghadam, Khodadady, and Zabihi (2011) and Uteubayeva, Kultanova, and Pastushenko (2012) suggested that creative thinking skills and exposure to second languages were related to each other, whereas Uteubayeva et al. (2012) argued that creativity could be a basis for second language learning. In addition, research studies by Cross (2012), Akinwamide and Adedara (2012), Feuer (2011), Meera and Remya (2010), and Hajilou, Yazdani, and Shokrpour (2012) suggested that creativity positively affected the second language learning process, whereas Luk (2013) and Schultz (2011) suggested that language creativity was an essential aspect of bilingual societies. Furthermore, studies by Kharkhurin (2010) and Leikin (2012) suggested that bilingualism may positively impacted creativity.

Recent research studies that investigated the links between creative thinking skills and second language learning suggested that positive links may existed between creative thinking skills and second language learning and that bilingualism positively impacted creative thinking skills (Kharkhurin, 2010; Leikin, 2012). However, recent research studies did not investigate whether second language learning contributed to the development of creative thinking skills.

The literature review revealed two recent research studies (Ghonsoly \& Showqi, 2012; Sehic, 2016) that sought to investigate the effects of second language learning on creative thinking skills in the domains of fluency, flexibility, originality, and elaboration.

Ghonsoly et al.'s research study (2012) involved 120 Iranian female college learners, 60 of whom were monolingual and 60 of whom were advanced English language learners. They tested the participants' creative thinking skills in the domains of fluency, flexibility, originality, and elaboration using the Torrance Test of Creative Thinking, and they analyzed the results one-way ANOVA. The results indicated that advanced English language learners achieved significantly higher test scores than monolingual learners in all four domains of creativity.

In addition, Sehic (2016) conducted a research study that focused on college learners of both genders in the United States to determine whether those who had successfully completed a college-level second language course(s) performed better in the domains of fluency, flexibility, originality, and elaboration, as measured using the Alternate Uses Test, than those who did not take a second language course(s). A MANOVA test revealed that college-level learners who completed a second language course(s) achieved higher mean scores in all four domains of creative thinking skills, but there was a statistically significant difference in the domain of flexibility alone: College-level learners of both genders who completed a second language course(s) achieved statistically significantly higher scores than those who did not (Sehic, 2016).

The research studies by Ghonsoly et al. (2012) and Sehic (2016) provided new insights into the effects of second language learning on creative thinking skills. However, additional research studies with different participants, research methods, and research designs will have to be necessary for an improved understanding of the effects of second language learning on creative thinking skills.

Therefore, the purpose of this sequential explanatory mixed-methods case study is to investigate whether a group of seven newly arrived immigrants in the United States who were enrolled in ESL classes at a community college in the northeastern United States will have better posttest than pretest performance in the domains of fluency, flexibility, originality, and elaboration as measured using the Alternate Uses Test and to build on existing research studies on this topic (Ghonsooly \& Showqi, 2012; Kharkhurin, 2010; Pishghadam et al., 2011; Sehic, 2016).

\section{Research Questions and Hypothesis}

\subsection{Research Questions}

RQ1: What difference, if any, is there between ESL learners and monolingual individuals regarding fluency, flexibility, originality, and elaboration as measured with the Alternate Uses Test? 
RQ2: What difference, if any, is there between the pretest and posttest scores of ESL learners, who have been learning English for two consecutive months, in the domains of fluency, flexibility, originality, and elaboration as measured with the Alternate Uses Test?

$R Q 3:$ What opinions do ESL learners in this mixed-methods case study have regarding ESL program?

$R Q 4$ : Do ESL learners in this mixed-methods case study make equal pretest and posttest efforts?

\subsection{Hypotheses}

H01: ESL learners and monolingual individuals in this mixed-methods case study will not score significantly differently in terms of fluency, flexibility, originality, and elaboration as measured with the Alternate Uses Test.

HA1: ESL learners and monolingual individuals in this mixed-methods case study will score significantly differently in terms of fluency, flexibility, originality, and elaboration as measured with the Alternate Uses Test.

H02: ESL learners in this mixed-methods case study will not have significantly different pretest and posttest scores in terms of fluency, flexibility, originality, and elaboration.

HA2: ESL learners in this mixed-methods case study will have significantly different on pretest and posttest scores in terms of fluency, flexibility, originality, and elaboration.

\section{Methodology}

\subsection{Research Method and Design(s)}

The present research study is a case study based on a sequential explanatory mixed-methods approach and a case study is defined a "a strategy of inquiry in which the researcher explores in depth a program, event, activity, process, or one or more individuals" (Creswell, 2009, p. 13). It was appropriate to select a case study designed for this research because it sought to investigate in depth the effects of second language learning on creative thinking skills by focusing on a smaller group of participants than those in the research studies by Ghonsoly et al. (2012) and Sehic (2016).

A sequential explanatory mixed-methods research design was used because the data was collected using quantitative methods (quasi-experimental research design) followed by a qualitative method (face-to-face interviewing). The design in question "is characterized by the collection and analysis of quantitative data in a first phase of research followed by the collection and analysis of qualitative data in a second phase that builds on the results of the initial quantitative results" (Creswell, 2009, p. 211). The literature review did not reveal any recent research studies on this topic that used a sequential explanatory mixed-methods design or a mixed-methods design in general. Therefore, this research study may provide new insights into the links between English language learning and creative thinking skills.

\subsection{Participants}

A total of 12 individuals voluntarily participated in this research study. The experimental group included six newly arrived immigrants and refugees whose first language was not English and who were enrolled in an ESL program that a community college in the northeastern United States offered. The control group included six local monolingual residents whose first language was English. All the participants received case numbers to protect their identities. Moreover, each case number consisted of a number and two letters. The first numerical digit indicated the sequence number of the participant $(1,2,3, \ldots 12)$, the first letter indicated the group to which the participant belonged ( $\mathrm{E}=\mathrm{ESL}$ group; $\mathrm{M}=$ Monolingual group), and the second letter indicates the participants' gender ( $\mathrm{M}=$ Male; $\mathrm{F}=$ Female). For instance, case number $2 \mathrm{MM}$ meant "participant number 2, monolingual group, male," whereas 12EF meant "participant number 12, ESL group, female."

\subsection{Materials}

\subsubsection{Alternate Uses Test}

The Alternate Uses Test was used to test participants' creative thinking skills in the domains of fluency, flexibility, originality, and elaboration (Appendix A). This test is also known as Guilford's Alternate Uses Test, and the American psychologist Joy Paul Guilford designed it to test divergent thinking skills in the domains of fluency, flexibility, originality, and elaboration (Chermahini, Hickendorff, \& Hommel, 2012). The Alternate Uses test can be administrated as a 12-item, 9-item, or 6-item test and is commonly used to test creative thinking skills. The 9-item version of the Alternate Uses Test was used to test participants' creative thinking skills in four different domains: flexibility, fluency, originality, elaboration. 
Flexibility. This dependent variable is defined as "the number of different categories of relevant responses being used" in solving a given problem (Ghonsooly \& Showqi, 2012, p. 163). This variable would be measured by an interval scale using the units from the Alternate Uses test.

Fluency. This dependent variable is defined as "the number of ideas and solutions" used in solving a given problem (Ghonsooly \& Showqi, 2012, p. 163). This variable would be measured by an interval scale using the units from the Alternate Uses test.

Originality. This dependent variable is defined as "the rarity of ideas" used in solving a problem (Ghonsooly \& Showqi, 2012, p. 163). This variable would be measured by an interval scale using the units from the Alternate Uses test.

Elaboration. This dependent variable is defined as "the number of added ideas, and the ability to develop and elaborate on ideas" when solving a problem (Ghonsooly \& Showqi, 2012, p. 163). This variable would be measured by an interval scale using the units from the Alternate Uses test.

\subsubsection{Questionnaire}

A 7-item questionnaire list was used to collect qualitative data during the face-to-face interview (Appendix B). This face-to-face interview involved the participants from the ESL group. It sought to determine how they felt about the pretest and posttest, whether one test was more difficult than the other, whether they exerted more effort in one test than the other, whether they were satisfied with the ESL program they were attending, whether the ESL program helped them improve their English skills, whether there was anything they would change about the ESL program, and whether they found the tests to be interesting.

\subsection{Data Collection and Analysis}

Data collection and analysis was performed in three different stages.

\subsubsection{Stage 1 (Pretest-Quantitative Data)}

Participants from both groups were asked to complete the 9-item Alternate Uses Test. The testing was conducted on June 28, 2016, and June 29, 2016. The collected data was analyzed with the assistance of SPSS software. A one-way ANOVA test was used to compare the Alternate Uses Test scores in the domains of fluency, flexibility, originality, and elaboration. The statistical difference (Sig.) between the means of the test scores of the ESL group and the monolingual group was used to answer the research questions and to determine whether to retain or reject the null hypothesis (Coladarci et al., 2011). A $p$-value of less than $5 \%(p<0.05)$ indicated that there was a statistically significant difference between the score means. The null hypothesis for every research question for which the $p$-value was greater than $5 \%(p>0.05)$ was retained, and it was rejected for every research question for which the $p$-value proved to be less than $5 \%(p<0.05)$.

\subsubsection{Stage 2 (Posttest-Quantitative Data)}

Participants from the ESL group were asked to complete the same 9-item Alternate Uses Test from Stage 1. Participants 7EF and 12EF decided not to take the posttest and therefore, their results were used in data analysis at the Stage 1 but not in that at Stage 2. The participants in the monolingual group did not take the posttest. The data collection for Stage 2 was performed on September 1, 2016, and September 2, 2016. As was the case for Stage 1 data, the data collected in Stage 2 was analyzed with the assistance of SPSS computer software. A one-way ANOVA test was used to compare the Alternate Uses Test scores in the domains of fluency, flexibility, originality, and elaboration. The statistical difference (Sig.) between the mean of the pretest scores and that of the posttest scores of the ESL group was used to answer research questions and to determine whether to retain or reject the null hypothesis (Coladarci et al., 2011). A $p$-value of less than $5 \%(p<0.05)$ indicated that there was a statistically significant difference between the score means. The null hypothesis for every research question for which the $p$-value was greater than $5 \%(p>0.05)$ was retained, and it was rejected for every research question for which the $p$-value proved to be less than $5 \%(p<0.05)$.

\subsubsection{Stage 3 (Interviews-Qualitative Data)}

Qualitative data was collected through face-to-face interviews between the researcher and the participants from the ESL group. Only the participants from the ESL group who completed the posttest were interviewed. The interviews were conducted on September 13, 2016, and September 15, 2016.

\section{Results}

\subsection{Stage 1 (Pretest-Quantitative Data)}

The descriptive statistics results for the monolingual group are presented in Table 1, and the results for the ESL 
group are presented in Table 2. These results suggest that the monolingual participants achieved higher mean scores in the domains of flexibility and originality, whereas the participants from the ESL group achieved higher mean scores in the domains of fluency and elaboration (see Table 3).

-Fluency: Monolingual group ( $\mathrm{M}=40.5 ; \mathrm{SD}=14.84)$; $\mathrm{ESL}$ group $(\mathrm{M}=47.5 ; \mathrm{SD}=7.89)$

-Flexibility: Monolingual group ( $\mathrm{M}=29.8 ; \mathrm{SD}=12.51)$; ESL group $(\mathrm{M}=21.0 ; \mathrm{SD}=10.56)$

-Originality: Monolingual group ( $\mathrm{M}=7.5 ; \mathrm{SD}=11.34)$; $\mathrm{ESL}$ group $(\mathrm{M}=3.5 ; \mathrm{SD}=2.50)$

-Elaboration: Monolingual group ( $M=11.16$; $S D=15.60)$; ESL group $(M=30.16 ; S D=15.99)$

The results of the one-way ANOVA test indicate that there were no statistically significant differences in the Alternate Uses Test performance in the domains of fluency, flexibility, originality, and elaboration between the ESL group and the monolingual group (see Table 4).

-Fluency: (Sig. $=0.332 ; p>0.05)$

-Flexibility: (Sig. $=0.216 ; p>0.05)$

-Originality: (Sig. $=0.419 ; p>0.05)$

-Elaboration: (Sig. $=0.064 ; p>0.05)$

Based on the results of the one-way ANOVA test, the null hypothesis (H01) for the first research question (RQ1) was not rejected. The answer to the first research question (RQ1) follows: ESL learners and monolingual individuals from this mixed-methods case study did not have significantly different scores in terms of fluency, flexibility, originality, and elaboration as measured with the Alternate Uses Test.

Table 1. The test results for monolingual group: alternate uses test scores

\begin{tabular}{lllll}
\hline Case & Fluency & Flexibility & Originality & Elaboration \\
\hline $1 \mathrm{MF}$ & 51 & 22 & 0 & 15 \\
$2 \mathrm{MM}$ & 21 & 16 & 4 & 3 \\
$3 \mathrm{MF}$ & 24 & 19 & 7 & 1 \\
$4 \mathrm{MM}$ & 53 & 38 & 4 & 7 \\
$5 \mathrm{MM}$ & 40 & 37 & 0 & 0 \\
$6 \mathrm{MF}$ & 54 & 47 & 30 & 41 \\
\hline
\end{tabular}

Note. The "Case" column includes all participants from monolingual group that are represented by the case codes.

Table 2. The pretest results for ESL group: alternate uses test scores

\begin{tabular}{lllll}
\hline Case & Fluency & Flexibility & Originality & Elaboration \\
\hline $7 \mathrm{MF}$ & 54 & 40 & 6 & 32 \\
$8 \mathrm{EM}$ & 53 & 15 & 1 & 53 \\
$9 \mathrm{EM}$ & 46 & 19 & 6 & 13 \\
$10 \mathrm{EF}$ & 54 & 19 & 4 & 24 \\
$11 \mathrm{EF}$ & 44 & 24 & 4 & 44 \\
$12 \mathrm{EF}$ & 34 & 9 & 0 & 15 \\
\hline
\end{tabular}

Note. The "Case" column includes all participants from ESL group that are represented by the case codes. 
Table 3. Descriptive statistics: alternate uses test mean scores by group

\begin{tabular}{llll}
\hline Variable & Mean & $\mathrm{SD}$ & $\mathrm{N}$ \\
\hline Fluency & $\mathrm{M}=40.5$ & 14.84 & 6 \\
Flexibility & $\mathrm{E}=47.5$ & 7.89 & 6 \\
& $\mathrm{M}=29.83$ & 12.51 & 6 \\
Originality & $\mathrm{E}=21.00$ & 10.56 & 6 \\
& $\mathrm{M}=7.50$ & 11.34 & 6 \\
Elaboration & $\mathrm{E}=3.50$ & 2.50 & 6 \\
& $\mathrm{M}=11.16$ & 15.60 & 6 \\
\hline
\end{tabular}

Note. $M=$ Monolingual group. $E=$ ESL group.

Table 4. The results of one-way ANOVA for monolingual and ESL group from the pretest stage

\begin{tabular}{llllll}
\hline Variable & Sum of Squares & df & Mean Square & F & Sig. \\
\hline Fluency & 147.00 & 1 & 147.000 & 1.040 & 0.332 \\
Flexibility & 234.083 & 1 & 234.083 & 1.746 & 0.216 \\
Originality & 48.000 & 1 & 48.000 & 0.711 & 0.419 \\
Elaboration & 1083.000 & 1 & 1083.000 & 4.340 & 0.064 \\
\hline
\end{tabular}

Note. A p-value of less than $5 \%(p<0.05)$ was used to determine a statistically significant difference between the score means.

\subsection{Stage 2 (Posttest-Quantitative Data)}

The results from Stage 2 indicated that the ESL participants who remained in the research study and studied the language for approximately two months achieved higher mean scores in the domains of flexibility, originality, and elaboration as measured with the Alternate Uses Test. However, their mean scores in the domain of fluency did not increase. (see Table 7).

-Fluency: Pretest ( $\mathrm{M}=49.25 ; \mathrm{SD}=4.99)$; Posttest $(\mathrm{M}=46.50 ; \mathrm{SD}=12.47)$

-Flexibility: Pretest ( $M=19.25 ; \mathrm{SD}=3.68)$; Posttest $(\mathrm{M}=20.25 ; \mathrm{SD}=2.21)$

-Originality: Pretest $(\mathrm{M}=3.75 ; \mathrm{SD}=2.06)$; Posttest $(\mathrm{M}=4.50 ; \mathrm{SD}=1.91)$

-Elaboration: Pretest $(\mathrm{M}=33.50 ; \mathrm{SD}=18.26)$; Posttest $(\mathrm{M}=36.25 ; \mathrm{SD}=23.97)$

The results of the one-way ANOVA test indicated that there was no statistically significant difference between ESL participants' performance in the pretest (Stage 1) and their performance in the posttest (Stage 2) of the Alternate Uses test in the domains of fluency, flexibility, originality, and elaboration between the ESL participants does not exist (see Table 8).

-Fluency: (Sig. $=0.697 ; p>0.05)$

-Flexibility: (Sig. $=0.658 ; p>0.05)$

-Originality: (Sig. $=0.613 ; p>0.05)$

-Elaboration: (Sig. $=0.861 ; p>0.05$ )

Based on the results of the one-way ANOVA test, the null hypothesis (H02) for the second research question (RQ2) was not rejected. The answer to the second research question (RQ2) is: ESL learners from this mixed-methods case study did not score significantly differently on the pretest and the posttest in terms of fluency, flexibility, originality, and elaboration. 
Table 5. The pretest results for ESL group: alternate uses test scores

\begin{tabular}{lllll}
\hline Case & Fluency & Flexibility & Originality & Elaboration \\
\hline $7 \mathrm{MF}$ & - & - & - & - \\
$8 \mathrm{EM}$ & 53 & 15 & 1 & 53 \\
$9 \mathrm{EM}$ & 46 & 19 & 6 & 13 \\
$10 \mathrm{EF}$ & 54 & 19 & 4 & 24 \\
$11 \mathrm{EF}$ & 44 & 24 & 4 & 44 \\
$12 \mathrm{EF}$ & - & - & - & - \\
Mean & 49.3 & 19.25 & 3.8 & 33.5 \\
\hline
\end{tabular}

Note. Participants $7 E F$ and $12 E F$ have decided to leave the research study and not participate at Stage 2. The mean scores are based on the pretest results of the participants who remained to participate in the research study.

Table 6. The posttest results for ESL group: alternate uses test scores

\begin{tabular}{lllll}
\hline Case & Fluency & Flexibility & Originality & Elaboration \\
\hline $7 \mathrm{MF}$ & - & - & - & - \\
$8 \mathrm{EM}$ & 54 & 19 & 2 & 55 \\
$9 \mathrm{EM}$ & 50 & 21 & 6 & 6 \\
$10 \mathrm{EF}$ & 54 & 18 & 6 & 56 \\
$11 \mathrm{EF}$ & 28 & 23 & 4 & 28 \\
$12 \mathrm{EF}$ & - & - & - & - \\
Mean & 46.50 & 20.25 & 4.50 & 36.25 \\
\hline
\end{tabular}

Note. The cases without results belong to the participants who left the research study.

Table 7. Descriptive statistics: pretest and posttest alternate uses test scores for ESL group

\begin{tabular}{llll}
\hline Variable & Mean & SD & N \\
\hline Fluency & Pretest $=49.25$ & 4.99 & 4 \\
Flexibility & Posttest $=46.50$ & 12.47 & 4 \\
& Pretest $=19.25$ & 3.68 & 4 \\
Originality & Posttest $=20.25$ & 2.21 & 4 \\
& Pretest $=3.75$ & 2.06 & 4 \\
Elaboration & Posttest $=4.50$ & 1.91 & 4 \\
& Pretest $=33.50$ & 18.26 & 4 \\
& Posttest $=36.25$ & 23.97 & 4 \\
\hline
\end{tabular}


Table 8. The results of one-way ANOVA for pretest and posttest results of ESL group

\begin{tabular}{llllll}
\hline Variable & Sum of Squares & $\mathrm{df}$ & Mean Square & $\mathrm{F}$ & Sig. \\
\hline Fluency & 15.125 & 1 & 15.125 & 0.168 & 0.697 \\
Flexibility & 2.000 & 1 & 2.000 & 0.216 & 0.658 \\
Originality & 1.125 & 1 & 1.125 & 0.284 & 0.613 \\
Elaboration & 15.125 & 1 & 15.125 & 0.33 & 0.861
\end{tabular}

Note. A p-value of less than $5 \%(p<0.05)$ was used to determine a statistically significant difference between the score means.

\subsection{Stage 3 (Face-to-Face Interviews-Qualitative Data)}

According to the qualitative data, all the participants from the ESL group who completed the pretest and posttest were satisfied with the ESL program that they were attending (Question \#5) and agreed that it helped them to learn English and improve their English skills (Question \#6). In addition, the qualitative data suggested that participants 4EF and 5EF were not willing to change the ESL program, whereas participants 2EM and 3EM were willing to add additional activities to it but not to omit any existing activities from it (Question \#7). Based on the qualitative data, the ESL participants who completed this mixed-methods case study research were satisfied with the ESL program that they were attending. They felt that the ESL program was helping them to learn English and did not want to omit anything from it.

The qualitative data revealed that the participants had different approaches to the Alternate Uses Test. Participants 4EF and 5EF found the posttest to be easier than the pretest, whereas participants 2EM and 3EM found the tests similarly complex (Question \#1).

The qualitative data suggested that most participants found the pretest more interesting than the posttest. Participants 4EF, 3EM, and 5EF found the pretest more interesting than the post test, whereas participant 2EM found both tests equally interesting (Question \#2).

Regarding effort, the qualitative data revealed mixed results. The majority of the participants (participants 4EF, $2 \mathrm{EM}$, and $5 \mathrm{EF}$ ) stated that they worked hard on both tests, whereas only participant 3EM stated that he worked harder on the pretest (Question \#3). However, the qualitative data suggested that participants 3EM and 5EF exerted greater effort in the pretest, whereas participant $2 \mathrm{EF}$ exerted equal amounts of effort in the pretest and posttest, and participant 4EF exerted greater effort in the posttest (Question \#4). Therefore, participant 4EF's and participant 5EF's answers to questions \#3 and \#4 may be contradictory.

Table 9

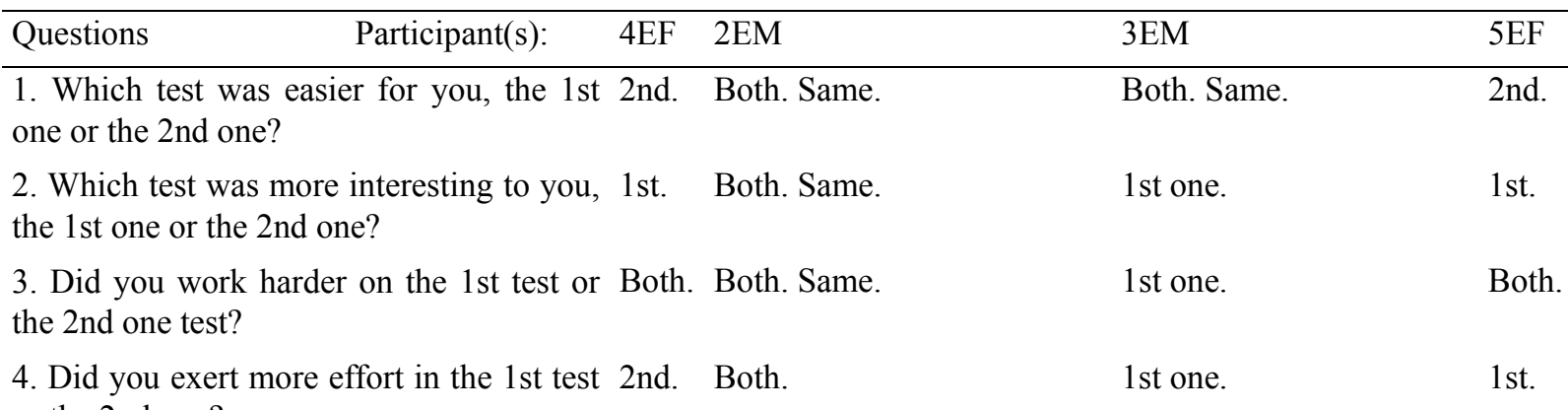
or the 2nd one?

5. Are you satisfied with the ESL Yes. Yes. I like it. I did not know Yes. Yes. program you are attending? how to use future and past tense. Now, I do.

6. Do you think that this ESL program is Yes. Yes. Yes. Yes. helping you to learn English language and improve your English skills?

No. Yes. I would like to learn I would like to add more No more about GED so that I "listening exercises" and 
can take GED.

make it more advanced.

Note. The face-to-face interview was conducted with ESL participates who completed pretest and the posttest.

\section{Discussion}

The purpose of this mixed methods case study was to investigate whether English language learning would affect learners' creative thinking skills. It has roots in the quantitative ex post facto research study that Sehic (2016) conducted and the research studies that Ghonsooly and Showqi (2012), Hajilou et al. (2012), and Pishghadam et al. (2011) conducted. The literature review revealed a significant body of research studies that investigated link(s) between the second language learning and cognitive skills and a very limited number of studies that investigated the relationships between English language learning and creative thinking skills. Based on the results of previous research studies on English language learning and creative thinking skills, one could argue that a positive relationship exists between English language learning and creative thinking skills may.

However, previous research studies that investigated the relationship between English language learning and creative thinking skills, did not provide answers as to whether learning English language and new word acquisition were responsible for the improvements of those skills. In addition, the previous research studies mostly involved large number of participants, and the researchers were not in a position to personally meet with all the participants and to investigate their personal experiences during the studies. This research study was based on a mixed-methods case study design that combined quantitative research methods (a quasi-experimental research design) and a qualitative research method (face-to-face interviews). For the case study, it focused on a group of English language learners who were enrolled in ESL classes at a community college in the northeastern United States. The literature review did not include any research study about English language learning and cognitive skills that employed both quantitative and qualitative research designs in a case study. Therefore, the results of this research study will provide new insights into the relationship between English language learning and creative thinking skills.

In Stage 1 of the data collection process (the pretest), the Alternate Uses Test results of the ESL group were compared with those of the monolingual group to shed light on how the creative thinking skills of ESL learners compared with those of monolingual individuals. The results suggested that ESL participants achieved higher mean scores in the domains of fluency and elaboration whereas the monolingual participants achieved higher mean scores in the domains of flexibility and originality. An one-way ANOVA test suggested that there was no statistically significant difference between the test scores of the ESL group and those of the monolingual group. Therefore, based on the test results from Stage 1, it could be argued that creative thinking skills in the domains of fluency, flexibility, originality, and elaboration did not significantly differ between ESL learners and monolingual individuals.

The results of Stage 2 of the data collection process (the posttest), which was conducted approximately two months after the pretest, (and in ESL participants completed the same Alternate Uses Test after studying English for approximately two months) suggested that the ESL participants achieved higher mean scores in the domains of flexibility, originality, and elaboration than they did in the pretest in Stage 1. They did not achieve higher mean scores in the domain of fluency. An one-way ANOVA test suggested that there was no statistically significant difference between the mean pretest and posttest scores of the ESL participants. Based on the mean score increase in the domains of flexibility, originality, and elaboration, it could be hypothesized that learning English improved learners' creative thinking skills in the domains of flexibility, originality, and elaboration but not in the domain of fluency. Further longitudinal research studies that will investigate the effects of English language learning on creative thinking skills over longer periods of time will be necessary for an improved understanding of whether English language learning is responsible for improvements in learners' creative thinking skills.

At Stage 3, qualitative data was collected through face-to-face interviews to shed light on the quantitative data outcomes. The ESL participants who completed the pretest and posttest were satisfied with the ESL program they were attending and stated that it helped them to learn English. Based on the participants' responses it could be concluded that the ESL program was effective. Moreover, based on the participants' opinions about the effectiveness of the ESL program in the face-to-face interviews and the results of the mean scores from Stage 2 (the posttest), it could be further argued that an effective English language learning process would result in improvements in learners' critical thinking skills in the domains of flexibility, originality, and elaboration. However, further longitudinal research studies are necessary to shed light on the effects of English language 
learning on creative thinking skills in the domains of fluency, flexibility, originality, and elaboration.

The interviews may not have provided a firm answer to the question of whether the ESL participants exerted equal amounts of effort in the pretest and posttest. In quantitative research studies with quasi-experimental as well as experimental research designs in which testing is conducted at the pretest and posttest stages, it is crucial for the results that the participants exerted equal amounts of effort in the pretest and the posttest. Hence, further research studies are necessary to better determine whether participants who participate in quantitative research studies with quasi-experimental and experimental research designs exert the same amounts of effort in the posttest and the pretest.

The ultimate conclusions that one can draw from this mixed-methods case study follow:

-The ESL participants and monolingual participants did not have significantly different scores in the Alternate Uses Test in the domains of fluency, flexibility, originality, and elaboration.

-The ESL participants' mean posttest scores were higher than their mean pretest scores in the domains of flexibility, originality, and elaboration as measured with the Alternate Uses Test.

-The ESL participants were satisfied with the ESL program they were attending and felt that it helped them to learn English.

Recommendations for further research studies follow:

-Longitudinal research studies that would investigate whether learning English language over an extended period (that is more than two months) would increase learners' creative thinking skills.

-Research studies that would investigate whether the participants in quantitative research studies with quasi-experimental and experimental research designs exerted equal amounts of pretest and posttest effort.

\section{References}

Adescope, O., Laving, T., Thompson, T., \& Ungerleider, C. (2010). A systematic review and meta-analysis of the cognitive correlates of bilingualism. Review of Educational Research, 80(2), 207-245. https://doi.org/10.3102/0034654310368803

Adi-Japha, E., Berberich-Artzi, J., \& Libnawi, A. (2010). Cognitive flexibility in drawings of bilingual children. Child Development. 81(5), 1356-1366. https://doi.org/10.1111/j.1467-8624.2010.01477.x

Akinwamide, T. K. \& Adedara, O. G. (2012). Facilitating autonomy and creativity in second language learning through cyber-tasks, hyperlinks and net-surfing. English Language Teaching, 5(6), 36-42.

Chermahini, S. A., Hickendorff, M., \& Hommel, B. (2012). Development and validity of a Dutch version of the remote associates task: An item-response theory approach. Thinking Skills and Creativity, 7, 177-186. https://doi.org/10.1016/j.tsc.2012.02.003

Coladarci, T., Cobb, C., Minium, E., \& Clarke, R. (2011). Fundamentals of statistical reasoning in education (3rd, ed.). Hoboken, NJ: John Wiley \& Sons, Inc.

Creswell, J. W. (2009). Research design: Qualitative, quantitative, and mixed methods approaches. Thousand Oaks, CA: Sage Publishing, Inc.

Cross, R. (2012). Creative in finding creativity in the curriculum: The CLIL second language classroom. The Australian Association for Research in Education, 39, 431-445. https://doi.org/10.1007/s13384-012-0074-8

Feuer, A. (2011). Developing foreign language skills, competence and identity through a collaborative creative writing project. Language, Culture and Curriculum, 24(2), 125-139. https://doi.org/10.1080/07908318.2011.582873

Filippi, R., Leech, R., Thomas, M. S. C., Green, D. W., \& Dick, F. (2012). A bilingual advantages in controlling language interference during sentence comprehension. Bilingualism: Language and Cognition, 15(4), 858-872. https://doi.org/10.1017/S1366728911000708

Ghonsooly, B., \& Showqi, S., (2012). The effects of foreign language learning on creativity. English Language Teaching, 5(4), 161-167. https://doi.org/10.5539/elt.v5n4p161

Greenberg, A., Bellana, B., \& Bialystok, E. (2013). Perspective-taking ability in bilingual children: Extending advantages in executive control to spatial reasoning. Cognitive Development, 28, 41-50. https://doi.org/10.1016/j.cogdev.2012.10.002

Hajilou, Y., Yazdani, H., \& Shokrpour, H. (2012). The relationship between Iranian EFL learners' creativity and 
their lexical and production knowledge. English Language Teaching, 5(3), 131-146.

Hernández, M., Costa, A., Fuentes, L. J., Vivas, A. B., Sebastián-Gallés, N. (2010). The Impact of bilingualism on the executive control and orienting networks of attention. Bilingualism: Language and Cognition, 13(3), 315-325. https://doi.org/10.1017/S1366728909990010

Kalashnikova, M. \& Mattock, K. (2014). Maturation of executive functioning skills in early sequential bilingualism. International Journal of Bilingual Education and Bilingualism, 17(1), 111-123. https://doi.org/10.1080/13670050.2012.746284

Kempert, S., Hardy, I., \& Saalbach, H. (2011). Cognitive benefits and costs of bilingualism in elementary school students: The case of mathematical word problems. Journal of Educational Psychology, 103(3), 547-561. https://doi.org/10.1037/a0023619

Kharkhurin, V. A. (2010). Bilingual verbal and nonverbal creative behaviour. International Journal of Bilingualism, 14(2), 211-226. https://doi.org/10.1177/1367006910363060

Kushalnagar, P., Hannay, H. J., \& Hernandez, A. E. (2010). Bilingualism and attention: A study of balanced and unbalanced bilingual deaf users of American sign language. Journal of Deaf Studies and Deaf Education, 15(3), 263-273. https://doi.org/10.1093/deafed/enq011

Lauchlan, F., Parisi, M., \& Fadda, R. (2012). Bilingualism in Sardinia and Scotland: Exploring the cognitive benefits of speaking a 'minority' language. International Journal of Bilingualism, 17(1), 43-56. https://doi.org/10.1177/1367006911429622

Leikin, M. (2012). The effect of bilingualism on creativity: Developmental and educational perspectives. International Journal of Bilingualism, 17(4), 431-447. https://doi.org/10.1177/1367006912438300

Luk, J. (2013). Bilingual language plan and local creativity in Hong Kong. International Journal of Multilingualism, 10(3), 236-250. https://doi.org/10.1080/14790718.2013.808200

Marzecová, A., Asanowicz, D., Krivá, L., \& Wodniecka, Z. (2013). The effects of bilingualism on efficiency and lateralization of attentional networks. Bilingualism: Language and Cognition, 16(3), 608-623. https://doi.org/10.1017/S1366728912000569

Meera, K. P., \& Remya, P. (2010). Effects of extensive reading and creativity on achievements in English language. E-journal of All India Association for Educational Research, 22(1), 16-22.

Milbrandt, M., \& Milbrandt, L. (2011). Creativity: What are we talking about? Art Education, 64(1), 8-13.

Pishghadam, R., Khodadady, E., \& Zabihi, R. (2011). Learner creativity in foreign language achievement. European Journal of Educational Studies, 3(3), 465-472.

Poulin-Dubois, D., Blaye, A., Coutya, J., \& Bialystok, E. (2011). The effects of bilingualism on toddlers' executive functioning. Journal of Experimental Child Psychology, 108, 567-579. https://doi.org/10.1016/j.jecp.2010.10.009

Prior, A. \& Macwhinney, B. (2010). A bilingual advantage in task switching. Bilingualism: Language and Cognition, 13(2), 253-262. https://doi.org/10.1017/S1366728909990526

Romero, M., Hyvönen, P., \& Barbera E. (2012). Creativity in collaborative learning across the life span. Scientific Research, 3(4), 422-429. https://doi.org/10.4236/ce.2012.34066

Schulz, B. (2011). Syntactic creativity in second language English: wh-scope marking in Japanese-English interlanguage. Second Language Research, 27(2), 313-341. https://doi.org/10.1177/0267658310390503

Sehic, S. (2016). College-level second language courses and creative thinking skills: An ex post facto study (Doctoral dissertation). Retrieved from http://search.proquest.com/docview/1821932457

Soveri, A., Laine, M., Hämäläinen, H., \& Hugdahl, K. (2011). Bilingual advantage in attentional control: Evidence from the forced-attention dichotic listening paradigm. Bilingualism: Language and Cognitivion, 14(3), 371-378. https://doi.org/10.1017/S1366728910000118

Steby, S., Sindhupriya, C., Rupali, M., \& Swapna, N. (2010). Cognitive-linguistic abilities in bilingual children. All India Institute of Speech \& Hearing, 29(1), 1-11.

Sternberg, R. (2003). Wisdom, intelligence, and creativity synthesized. New York, NY: Cambridge University Press. https://doi.org/10.1017/CBO9780511509612

Uteubayeva, E. A., Kultanova, Z. M., \& Pastushenko, T. A. (2012). Creative thinking as a basis of foreign 
language learning by the method of project activities. Education and Science Without Borders, 3(5), 115-117.

Yang, S., Yang, H., \& Lust, B. (2011). Early childhood bilingualism leads to advances in executive attention: Dissociating culture and language. Bilingualism: Language and Cognition, 14(3), 412-422. https://doi.org/10.1017/S1366728910000611

\section{Appendix A: Alternate Uses test}

\section{Part I}

List as many as six possible uses for each of the following objects:

1. SHOE (used as footware)

a.

b.

c.

d.

e.

f.

2. BUTTON (used to fasten things)

a.

b.

c.

d.

e.

f.

Appendix B: Interview Questionnaire

1. Which test was easier for you, the 1 st one or the 2 nd one?

2. Which test was more interesting to you, the 1st one or the 2nd one?

3. Did you work harder on the 1 st test or the 2 nd one test?

4. Did you exert more effort in the 1st test or the 2nd one?

5.Are you satisfied with the ESL program you are attending?

6. Do you think that this ESL program is helping you to learn English language and improve your English skills?

7. Would you like to change something about the ESL program you are attending? 


\section{Copyrights}

Copyright for this article is retained by the author(s), with first publication rights granted to the journal.

This is an open-access article distributed under the terms and conditions of the Creative Commons Attribution license (http://creativecommons.org/licenses/by/4.0/). 